\title{
Motion-preserving treatment of unstable atlas fracture: transoral anterior C1-ring osteosynthesis using a laminoplasty plate
}

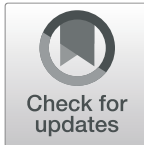

Xiaobao Zou ${ }^{1,2}$, Beiping Ouyang ${ }^{1,2}$, Binbin Wang ${ }^{2}$, Haozhi Yang ${ }^{2}$, Su Ge², Yuyue Chen², Ling Ni², Shuang Zhang ${ }^{2}$, Hong $\mathrm{Xia}^{2}$, Zenghui $\mathrm{Wu}^{2}$ and Xiangyang $\mathrm{Ma}^{1,2^{*}}$

\begin{abstract}
Background: C1-ring osteosynthesis is a valid alternative to posterior C1-C2 or C0-C2 fusion to preserve important $\mathrm{C} 1-\mathrm{C} 2$ motion in the treatment of unstable atlas fractures. Nevertheless, the fixation instruments used in current studies for transoral anterior C1-ring osteosynthesis were not suitable for anterior anatomy of the atlas or did not have reduction mechanism. We therefore present this report to investigate preliminary clinical effects of transoral anterior C1-ring osteosynthesis using a laminoplasty plate in unstable atlas fractures.

Methods: From January 2014 to December 2017, 13 patients with unstable atlas fractures were retrospectively reviewed. All patients were treated with transoral anterior C1-ring osteosynthesis using a laminoplasty plate. Preand postoperative images were obtained to assess reduction of the fracture, internal fixation placement, and bone union. Neurological function, range of motion, and pain levels were evaluated clinically on follow-up.

Results: The surgeries were successfully performed in all cases. The average follow-up duration was $16.6 \pm 4.4$ months (range 12-24 months). One patient suffered screw loosening after operation and underwent replacement operation subsequently. Satisfactory clinical outcomes were achieved in all patients with ideal fracture reduction, reliable plate placement, well-preserved range of motion, and neck pain alleviation. All patients achieved bone union of fractures without loss of reduction or implant failure or C1-C2 instability during the follow-up. No vascular or neurological complication was noted during the operation and follow-up.

Conclusions: Transoral anterior C1-ring osteosynthesis using a laminoplasty plate is a effective surgical treatment for unstable atlas fractures. This technique has a ingenious reduction mechanism, and can provide satisfactory bone union and preservation of $\mathrm{C} 1-\mathrm{C} 2$ motion.
\end{abstract}

Keywords: Transoral approach, Atlas fracture, Unstable fracture, C1-ring osteosynthesis, Open reduction, Internal fixation

\footnotetext{
* Correspondence: maxy1001@126.com

${ }^{1}$ The First School of Clinical Medicine, Southern Medical University, No.1838 North of Guangzhou Road, Guangzhou 510515, People's Republic of China 2Department of Orthopedics, General Hospital of Southern Theatre Command of PLA, 111 Liuhua Road, Guangzhou 510010, People's Republic of China
}

C C The Author(s). 2020 Open Access This article is licensed under a Creative Commons Attribution 4.0 International License, which permits use, sharing, adaptation, distribution and reproduction in any medium or format, as long as you give appropriate credit to the original author(s) and the source, provide a link to the Creative Commons licence, and indicate if changes were made. The images or other third party material in this article are included in the article's Creative Commons licence, unless indicated otherwise in a credit line to the material. If material is not included in the article's Creative Commons licence and your intended use is not permitted by statutory regulation or exceeds the permitted use, you will need to obtain permission directly from the copyright holder. To view a copy of this licence, visit http://creativecommons.org/licenses/by/4.0/ The Creative Commons Public Domain Dedication waiver (http://creativecommons.org/publicdomain/zero/1.0/) applies to the data made available in this article, unless otherwise stated in a credit line to the data. 


\section{Background}

Atlas fractures are not rare in cervical spine injury, account for $25 \%$ of craniocervical injuries, $2-13 \%$ of cervical injuries, $1-2 \%$ of all spinal injuries, and less likely to cause neurological deficits $[1,2]$. The stability of atlas fractures is determined by the structural integrity of the transverse atlantal ligament (TAL) and the extent of fracture $[3,4]$. The treatment of unstable atlas fractures is still controversial. Nonsurgical treatments of unstable atlas fractures have the disadvantages of deficient reduction and high rates of nonunion, and even neurological damage [5]. Although surgical treatments with $\mathrm{C} 1-\mathrm{C} 2$ or $\mathrm{C} 0-\mathrm{C} 2$ fusion can achieve satisfactory stability and bone fusion in unstable atlas fractures, the normal $\mathrm{C} 1-\mathrm{C} 2$ motion is lost [6]. Presently, C1-ring osteosynthesis is a wellknown and effective management for unstable atlas fractures to preserve important $\mathrm{C} 1-\mathrm{C} 2$ motion [2]. But, the devices used in previous researches for transoral anterior C1-ring osteosynthesis were not suitable for anterior anatomy of the atlas or did not have reduction mechanism [7-9]. In this study, we retrospectively analyzed the clinical data of 13 patients with unstable atlas fracture who were treated by transoral anterior C1-ring osteosynthesis using a laminoplasty plate presenting with a ingenious reduction procedure, and evaluated the preliminary effects of this technique.

\section{Methods}

\section{Patients}

From January 2014 to December 2017, 13 consecutive patients with unstable atlas fractures were recruited (Table 1). Transoral anterior C1-ring osteosynthesis using a laminoplasty plate was performed in each case. Patients included 6 men and 7 women with a mean age of 47.8 years (ranging from 32 to 66 years). The causes of injury were falling (5 cases) and motor vehicle accident (8 cases). All patients were conscious and cooperative and presented with neck pain and stiffness without neurological symptoms. Routine preoperative open-mouth, anteroposterior and lateral radiographs, computed tomography (CT) with 3dimensional reconstructions, and magnetic resonance imaging (MRI) were performed in each case. All cases in this study were unstable with combined fractures of the anterior and posterior atlantal arches based on multidetector CT, which were type II fractures according to Landells and Van Peteghem's classification system [10]. No patients had anterior or ratatory atlantoaxial dislocation. Nine patients had injuries of the TAL shown on MRI or CT images. Dickman type I and type II TAL injury [11] were found in 2 and 7 patients, respectively.

\section{Surgical procedure}

Preoperative preparation: All patients were instructed to gargle six times per day with $0.02 \%$ chlorhexidine acetate prior to surgery. A professional dental cleaning was also performed prior to surgery. A nasogastric feeding tube was placed and prophylactic broad-spectrum antibiotics were applied conventionally $30 \mathrm{~min}$ before the operation.

Surgical technique: Under general anesthesia with nasotracheal intubation, the patient was positioned supine, and the neck was situated to be slightly hyperextended. After routine oral cleaning and disinfection, oral cavity was opened by a Codman retractor. The anatomic land marks in all transoral operations can be confirmed under the guidance of intraoperative fluoroscopy. Then, a longitudinal incision of $3-4 \mathrm{~cm}$ was made in the median posterior pharyngeal wall to incise the mucosa and split longitudinal muscles. After the anterior arch of $\mathrm{C} 1$ and the anterior aspect of lateral mass and fracture of the atlas were exposed, an appropriately sized plate (Posterior cervical laminoplasty screw-plate system, Fule, China; Fig. 1) was shaped to suit for anterior arch. If the anterior arch had single fracture, a side of plate was fixed on the lateral mass near the fracture gap using one screw firstly. After a temporary reduction screw was inserted into the anterior arch through the sliding hole of the plate, a Cook hemostatic forceps was installed between a hole and temporary reduction screw. Then, the forceps handles were closed to impart a compression force to restore the fracture (Fig. 2a). After the reduction of fracture was confirmed under direct vision, another side of plate was fixed using two screws (Fig. 2b). Then, the last hole was implanted with a screw, and the temporary reduction screw was removed (Fig. 2c). If the anterior arch had double fractures, the reduction of fractures was performed by inward extrusion on the lateral masses using a Crutchfield clamp [8], and then, an appropriately sized plate was placed in front of the atlas to fix the fractures directly. After the placement of the plate and screws was verified by $\mathrm{C}$-arm fluoroscopy, the incision was closed in the muscular and mucosal layers.

\section{Postoperative management and follow-up}

After surgery, the tracheal cannula was removed after 24-48 $\mathrm{h}$, and the nasogastric feeding tube was removed after 7 days. Ultrasonic nebulization and $0.02 \%$ chlorhexidine acetate gargling were performed 3-5 times per day for 7 days. Cervical radiographs and CT scans were obtained 5 days postoperatively to evaluate fracture reduction and the position of fixation. The total lateral mass displacement (LMD) was also measured on the coronal CT images. Postoperative external immobilization with a rigid cervical collar was used for 4-6 weeks. Patients were followed up at 3, 6, 9 and 12 months and then once per year or whenever needed with assessment of neck pain on 


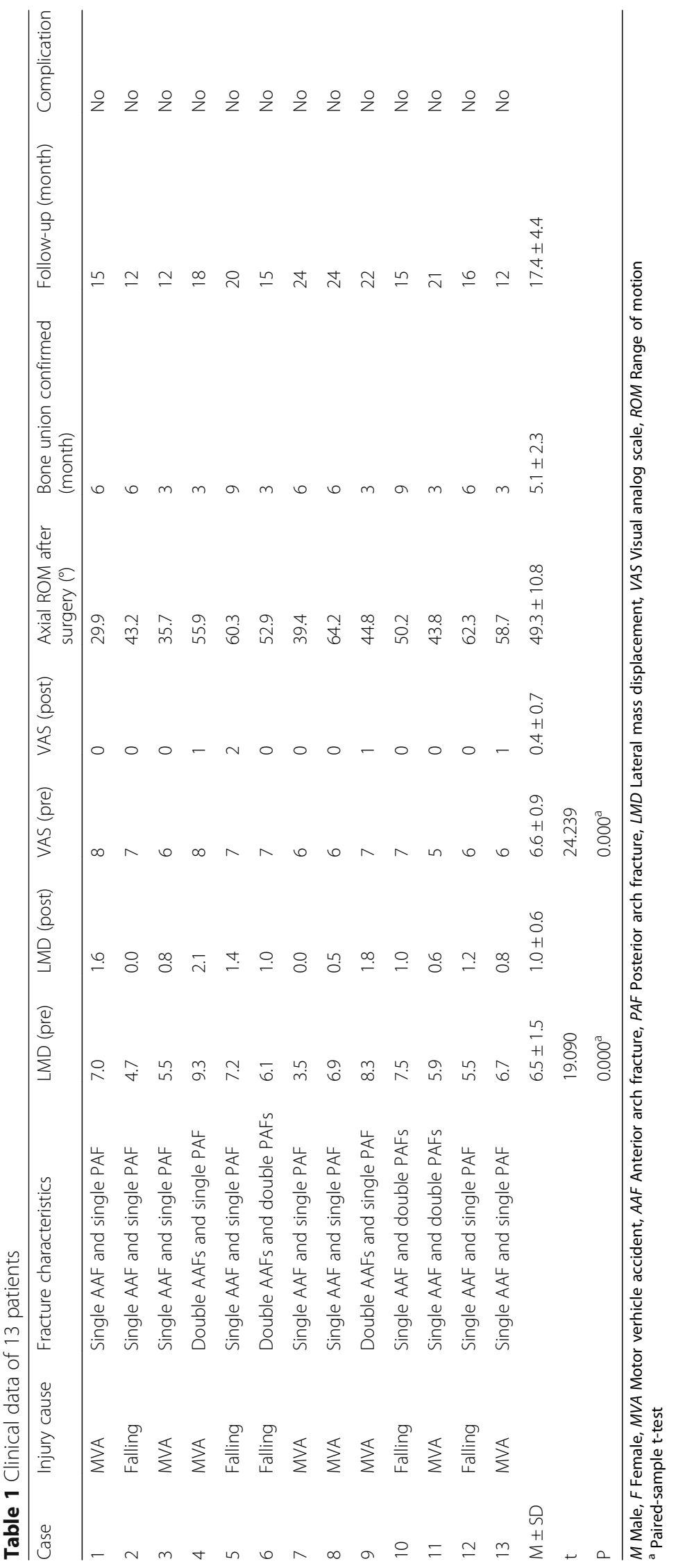




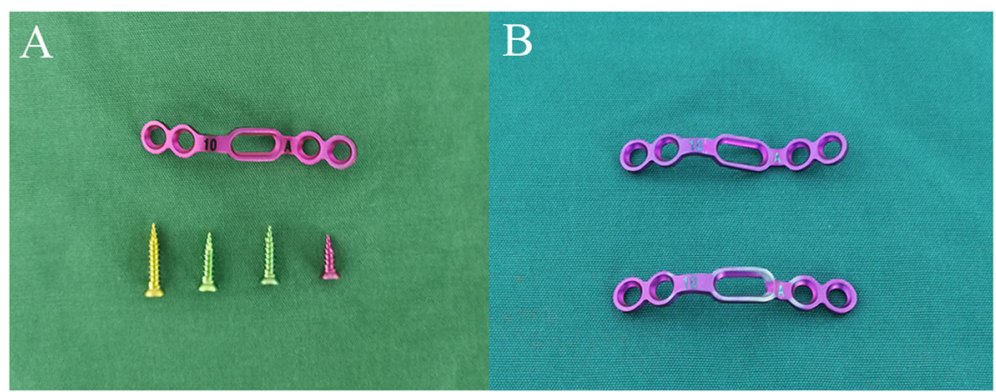

Fig. 1 Posterior cervical laminoplasty screw-plate system. a Laminoplasty plate and tapping screws in different lengths. b Laminoplasty plates before and after shaping

a visual analog scale (VAS), and with neurological status. Cervical radiographs and CT scans were performed at each follow-up. Bone union of fractures was evaluated by CT scan and confirmed by complete fusion of anterior arch fractures.

\section{Statistical analysis}

All data were subject to normal distribution based on K$\mathrm{S}$ test, which were expressed as the mean and standard deviation. The data were analyzed statistically with the paired-samples t-test, using SPSS 19.0 software (IBM, Armonk, NY, USA). The level of significance was set at $p<0.05$.

\section{Results}

The surgeries were performed successfully in all 13 cases. No damage to the spinal nerves, blood vessels, or dura mater occurred during the operations. The mean time of the procedure was $86.9 \pm 16.7 \mathrm{~min}$ (ranging from 60 to $120 \mathrm{~min}$ ), with an average intraoperative blood loss of $52.3 \pm 16.9 \mathrm{~mL}$ (ranging from 30 to $80 \mathrm{~mL}$ ). The average follow-up was $17.4 \pm 4.4$ months (ranging from 12 to 24 months). Postoperative CT scan showed wellplacement of plates and screws, and satisfactory reduction of fractures of the anterior and posterior atlantal arches in all cases. The postoperative LMD (1.0 \pm 0.6 $\mathrm{mm}$, ranging from 0.0 to $2.1 \mathrm{~mm}$ ) was significantly reduced compared with preoperative LMD $(6.5 \pm 1.5 \mathrm{~mm}$, ranging from 3.5 to $9.3 \mathrm{~mm} ; p<0.01$ ). One patient suffered screw loosening 1 week after operation and underwent replacement procedure subsequently. No internal fixation loosening or breakage was revealed following $\mathrm{CT}$ scans and plain radiographs during the follow-up. No complications of infection were noted. All patients achieved successful bone union of fractures after 3-9 months (Figs. 3 and 4). The axial range of motion was $49.3^{\circ} \pm 10.8^{\circ}$ (ranging from $29.9^{\circ}$ to $64.2^{\circ}$ ) at the final follow-up. All patients had a well-preserved range of motion of the upper cervical spine without signs of instability. Preoperative VAS scores $(6.6 \pm 0.9$; range $5-8)$ had a markedly decrease $(0.4 \pm 0.7$; range $0-2 ; p<0.01)$ at the final follow-up (Table 1).

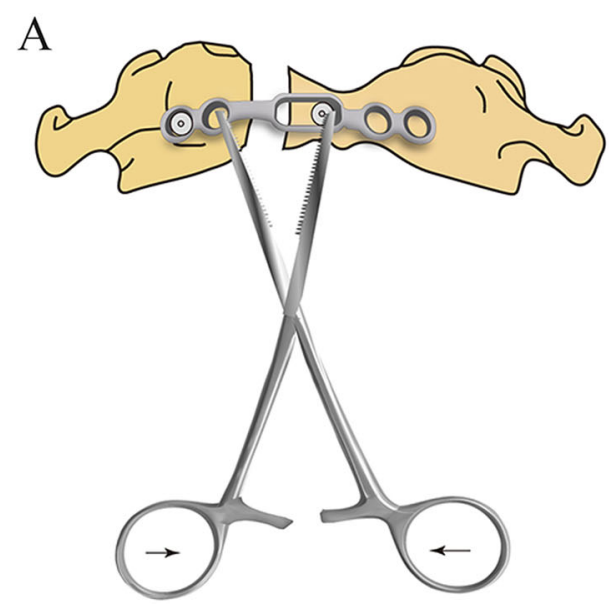

$\mathrm{B}$

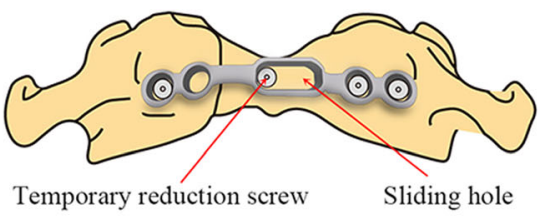

$\mathrm{C}$

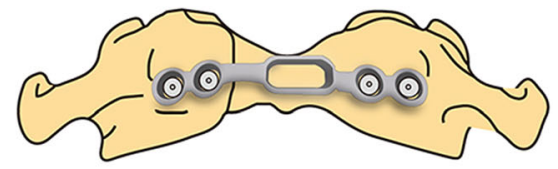

Fig. 2 Reduction schematics. a The forceps handles were closed to impart a compression force to reset the fracture after placement of one side of plate and temporary reduction screw. b Reduction of fracture was achieved, and another side of plate was fixed using two screws. c The last screw was placed, and the temporary reduction screw was removed 


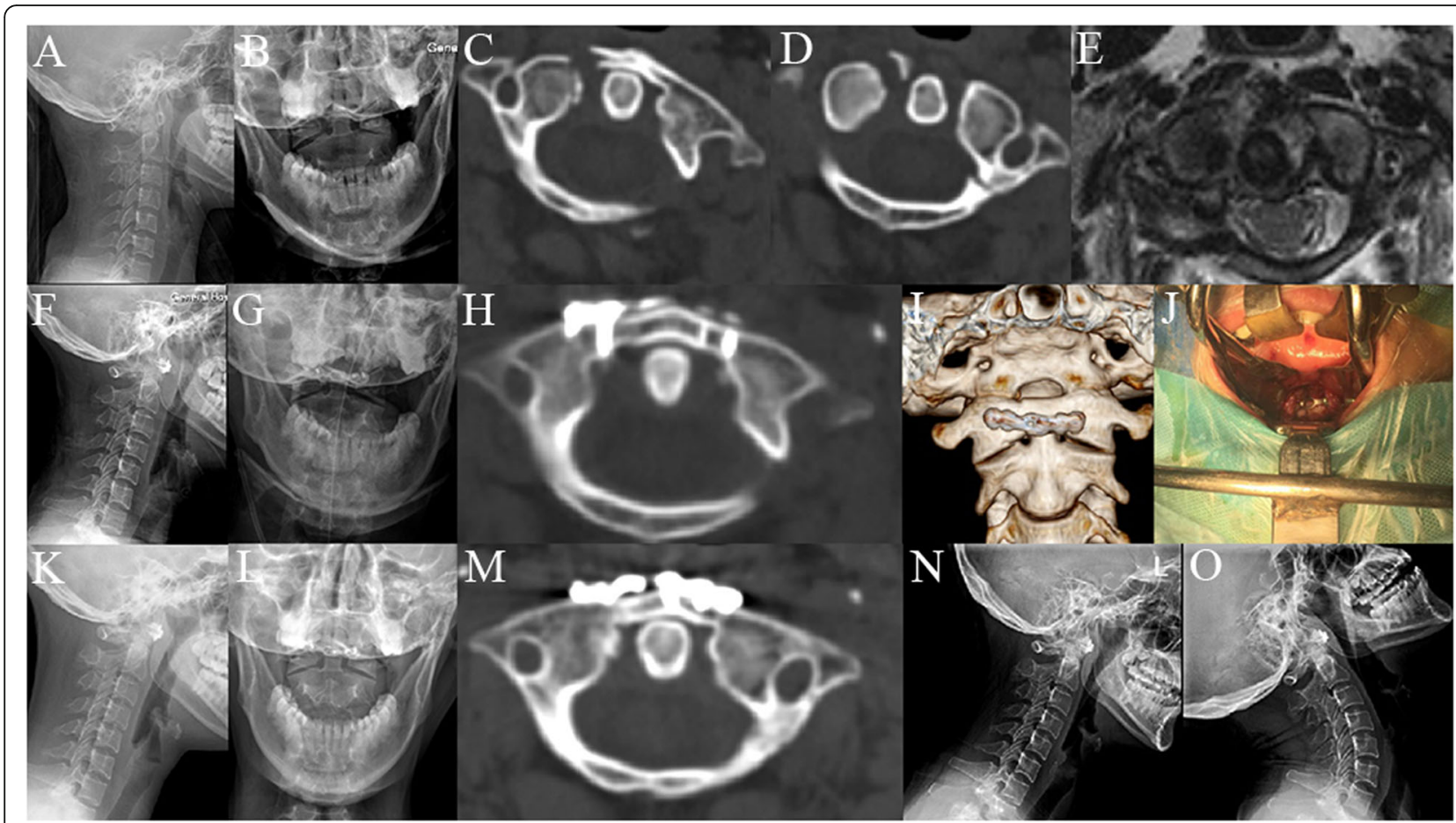

Fig.3 A 32-year-old female with atlas fracture treated by transoral anterior (1-ring osteosynthesis using a laminoplasty plate. Preoperative cervical lateral (a) and open-mouth X-rays (b), axial CT (c, d) and MRI images (e) showed combined fracture of the anterior and posterior arches with type I TAL injury. Postoperative cervical lateral (f) and open-mouth X-rays (g) identified the relatively good C1-C2 alignment. Axial CT (h) and the reconstructed images (i) after surgery showed reduction of the anterior arch fracture and optimal plate location. Transoral intraoperative view (j) showed good position of anterior laminoplasty plate fixation. Cervical lateral $(\mathbf{k})$ and open-mouth X-rays (I) at 6 months after surgery showed stable fixation. An axial CT image (m) at 6 months after surgery indicated solid bone union. The dynamic cervical X-rays (n, o) at final follow-up revealed no sign of instability of $\mathrm{C} 1-\mathrm{C} 2$ and no loosening of the fixation

\section{Discussion}

The atlas, the ring-shaped first cervical vertebra, does not have a vertebral body or spinous process. It is formed by the anterior and posterior arches and the two lateral masses. The weakest points of the atlas are the regions of the anterior and posterior arches that connect with the lateral masses, which are most likely to be injured with two or more fractures in the ring structure [12]. The stability of atlas fractures has historically been based primarily on the integrity of the TAL [2]. But, it is now believed that combined fractures of the anterior and posterior atlantal arches are the unstable fractures, whether or not they are associated with rupture of the TAL $[3,4,8]$.

Symptoms of neurological dysfunction are rare in patients with atlas fracture because fractures of the atlas ring increase the space that is available for the dural sac, thereby inhibiting compression [13]. So that, stabilization of fractures is the most important factor for the treatment of atlas fractures. Although there is an agreement regarding treatment of stable atlas fractures, the optimal management of unstable atlas fractures remains controversial. Previously, nonsurgical treatments with skull traction, followed by external halo-vest immobilization, has been commonly suggested [14]. Most patients are can be treated by external immobilization with satisfactory outcomes. However, a follow-up study of 22 patients with atlas burst fractures by Dvorak et al. [15] showed that patients that underwent conservative treatments failed to regain functional preoperative levels, and hinted that nonsurgical treatments were not optimal management options. The strongest Halo-vest has only $75 \%$ restriction on cervical flexion and extension activity, so that, preservative treatment with a Halo-vest has a high risk of nonunion [5]. Immobilization of the cervical spine for several months may result in significant discomfort and other complications especially in elderly patients [16]. Moreover, mechanical instability and incongruence of the atlanto-occipital and the atlantoaxial joints may lead to arthrosis, persistent neck pain, and even neurologic injury.

Posterior $\mathrm{C} 1-\mathrm{C} 2$ or $\mathrm{C} 0-\mathrm{C} 2$ fixation and fusion techniques are widely used in unstable atlas fractures, including $\mathrm{C} 1-\mathrm{C} 2$ transarticular screw fixation, $\mathrm{C} 1-\mathrm{C} 2$ screw-rod fixation, and $\mathrm{C} 0-\mathrm{C} 2$ plate-screw-rod fixation [17, 18]. These fixation techniques promote biomechanical stability and guarantee a high bone fusion rate [19-22]. However, these treatments sacrifice the normal motion of the $\mathrm{C} 1-$ 


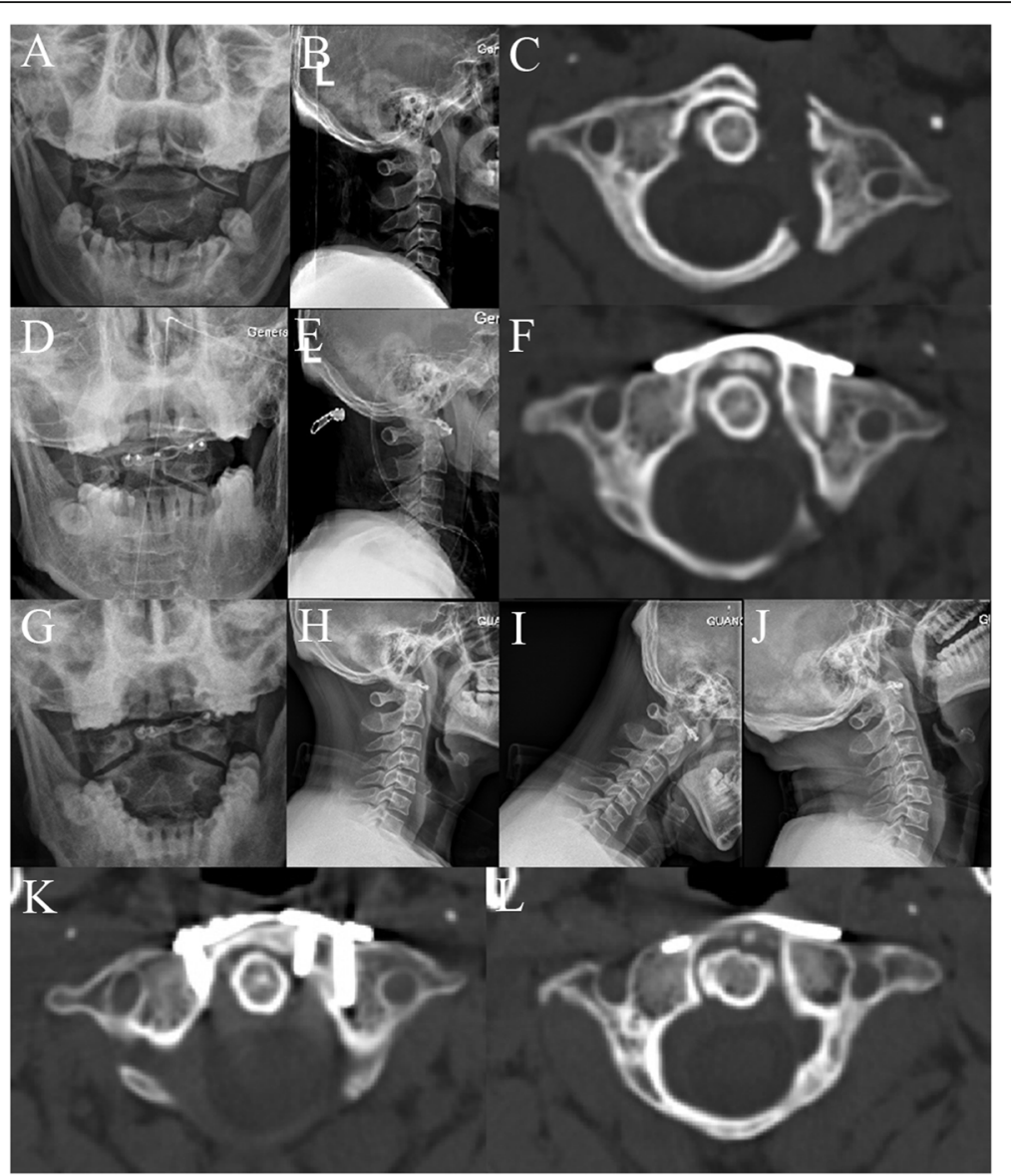

Fig.4 A 41-year-old female with atlas fracture treated by transoral anterior C1-ring osteosynthesis using a laminoplasty plate. Preoperative openmouth (a) and cervical lateral X-rays (b), and axial CT (c) showed combined fracture of the anterior and posterior arches. Postoperative openmouth (d) and cervical lateral X-rays (e) revealed the relatively good C1-C2 alignment. Axial CT (f) after surgery identified good reduction of the anterior and posterior arch fractures, and optimal placement of plate. Open-mouth $(\mathbf{g})$, cervical lateral $(\mathbf{h})$ and dynamic $\mathbf{X}$-rays $(\mathbf{i}, \mathbf{j})$ at 9 months after surgery showed reliable fixation without instability of C1-C2. Axial CT images $(\mathbf{k}, \mathbf{I})$ at 9 months after surgery indicated satisfactory bone union of anterior and posterior arch fractures

C2 joints and possible increase the incidence of subaxial cervical spine degeneration [2].

In 2004, Ruf et al. [7] firstly reported a motionpreserving technique, C1-ring osteosynthesis, using a lateral mass screw-rod construct by transoral approach for unstable atlas fractures, with favorable clinical outcomes. Dickman hypothesizes that permanent anterior instability of $\mathrm{C} 1-\mathrm{C} 2$ results from TAL rupture [23]. However, biomechanical studies showed that within the physiological loading range, the longitudinal ligaments had sufficient capacity to maintain the stability of the atlantoaxial joint even with concomitant TAL injuries in atlas fractures [24, 25]. C1-ring osteosynthesis may therefore be a valid alternative to $\mathrm{C} 1-\mathrm{C} 2$ fusion in the treatment of unstable atlas fractures even with TAL rupture $[7,8,26,27]$. But, a lateral mass screw-rod construct used by Ruf et al. [7] was not suitable for anterior anatomy of the atlas. Ma et al. [8] and $\mathrm{Hu}$ et al. [9] used a reconstruction plate in transoral anterior C1-ring osteosynthesis for unstable atlas fractures, but this plate did not have reduction mechanism. Thus, we performed transoral anterior C1-ring osteosynthesis for unstable atlas fractures using a laminoplasty plate which has a reduction function, that can restore fractures and preserve normal $\mathrm{C} 1-\mathrm{C} 2$ motion.

In our study, 13 patients with an unstable atlas fracture were treated with a laminoplasty plate C1-ring osteosynthesis by transoral anterior approach and were followed-up to assess the preliminary efficacy of this technique. This technique can not only reduce the fracture of anterior atlantal arches, but also reduce the dislocation of lateral mass, and at the same time, the fracture of posterior atlantal arches reduced automatically. All cases achieved satisfactory reduction of fractures, well-preserved range of motion and satisfactory bone union without signs of instability or complications. Wound infection can be a serious problem for the transoral anterior approach. But with proper preoperative 
preparation and postoperative care, the infection can be reduced and even prevented $[8,28]$. In this study, no signs and symptoms of infection were found after surgery and during the follow-up.

There are several limitations in the current study. First, the small sample size is the primary limitation. The safety and efficacy of this technique need to be evaluated with more cases. In addition, the present study is retrospective in nature; future prospective studies may better control for follow-up timing intervals and may have the potential to include more standardized outcome measures.

\section{Conclusions}

Transoral anterior C1-ring osteosynthesis using a laminoplasty plate is a effective surgical option to manage unstable atlas fractures. This technique can provide satisfactory reduction, reliable stabilization and bone union of fracture, and preserve important $\mathrm{C} 1-\mathrm{C} 2$ motion.

\section{Abbreviations}

TAL: Transverse atlantal ligament; CT: Computed tomography; MRI: Magnetic resonance imaging; LMD: Lateral mass displacement; VAS: Visual analog scale; MVA: Motor verhicle accident; AAF: Anterior arch fracture; PAF: Posterior arch fracture; ROM: Range of motion

\section{Acknowledgements}

We would like to thank Jianhua Wang, Kai Zhang, Fuzhi Ai for guidance of measurement of radiographic data.

\section{Authors' contributions}

MX designed the study and critically revised the manuscript. ZX carried out the statistical analyses, and drafted the manuscript. OB, WB, YH, GS, CY, NL, $\mathrm{ZS}$ were responsible for the data collection and measurement of radiographic data. $\mathrm{XH}, \mathrm{WZ}$ checked the manuscript. All authors read and approved the final manuscript.

\section{Funding}

This work was supported by the Guangzhou Municipal Science and Technology Project (No. 201803010046); the National Natural Science Foundation of China (No. 81672232); and the Science and Technology Planning Project of Guangdong Province (No. 2015B020233013).

\section{Availability of data and materials}

The data used and analyzed during the current study are available in anonymized form from the corresponding author on reasonable request.

\section{Ethics approval and consent to participate}

This study was approved by the ethics committee of General Hospital of Southern Theatre Command of PLA and the written informed consent for participation in the study was obtained.

\section{Consent for publication}

Written informed consent was obtained from all individual participants included in the study.

\section{Competing interests}

The authors declare that they have no competing interests.

Received: 29 April 2020 Accepted: 6 August 2020

Published online: 12 August 2020

\section{References}

1. Matthiessen C, Robinson Y. Epidemiology of atlas fractures--a national registry-based cohort study of 1,537 cases. Spine J. 2015;15:2332-7.
2. Zhang YS, Zhang JX, Yang QG, Li W, Tao H, Shen CL. Posterior osteosynthesis with monoaxial lateral mass screw-rod system for unstable C1 burst fractures. Spine J. 2018;18:107-14.

3. Lee $\mathrm{C}$, Woodring $\mathrm{JH}$. Unstable Jefferson variant atlas fractures: an unrecognized cervical injury. Am J Neuroradiol. 1991;12:1105-10.

4. Lee TT, Green BA, Petrin DR. Treatment of stable burst fracture of the atlas (Jefferson fracture) with rigid cervical collar. Spine (Phila Pa 1976). 1998;23: 1963-7.

5. Kim MK, Shin JJ. Comparison of radiological and clinical outcomes after surgical reduction with fixation or halo-vest immobilization for treating unstable atlas fractures. Acta Neurochir. 2019;161:685-93.

6. Kim HS, Cloney MB, Koski TR, Smith ZA, Dahdaleh NS. Management of isolated atlas fractures: a retrospective study of 65 patients. World Neurosurg. 2018;111:e316-22.

7. Ruf M, Melcher R, Harms J. Transoral reduction and osteosynthesis C1 as a function-preserving option in the treatment of unstable Jefferson fractures. Spine (Phila Pa 1976). 2004;29:823-7.

8. Ma W, Xu N, Hu Y, Li G, Zhao L, Sun S, Jiang W, Liu G, Gu Y, Liu J. Unstable atlas fracture treatment by anterior plate C1-ring osteosynthesis using a transoral approach. Eur Spine J. 2013;22:2232-9.

9. Hu Y, Albert TJ, Kepler CK, Ma WH, Yuan ZS, Dong WX. Unstable Jefferson fractures: results of transoral osteosynthesis. Indian J Orthop. 2014:48:145-51.

10. Landells CD, Van Peteghem PK. Fractures of the atlas: classification, treatment and morbidity. Spine (Phila Pa 1976). 1998;13:450-2.

11. Dickman CA, Greene KA, Sonntag VK. Injuries involving the transverse atlantal ligament: classification and treatment guidelines based upon experience with 39 injuries. Neurosurgery. 1996;38:44-50.

12. Teo EC, Ng HW. First cervical vertebra (atlas) fracture mechanism studies using finite element method. J Biomech. 2001;34:13-21.

13. Lleu M, Charles YP, Blondel B, Barresi L, Nicot B, Challier V, Godard J, Kouyoumdjian P, Lonjon N, Marinho P, Freitas E, Schuller S, Fuentes S, Allia J, Berthiller J, Barrey C. C1 fracture: analysis of consolidation and complications rates in a prospective multicenter series. Orthop Traumatol Surg Res. 2018;104:1049-54.

14. Kamal Y, Ortho MS, Khan HA, Gani N, Haq AU, Gul S, Singh D. Atlas and axis injuries role of Halovest. Int J Health Sci (Qassim). 2014;8:335-45.

15. Dvorak MF, Johnson MG, Boyd M, Johnson G, Kwon BK, Fisher CG. Longterm health-related quality of life outcomes following Jefferson-type burst fractures of the atlas. J Neurosurg Spine. 2005;2:411-7.

16. Horn EM, Theodore N, Feiz-Erfan I, Lekovic GP, Dickman CA, Sonntag VK. Complications of halo fixation in the elderly. J Neurosurg Spine. 2006;5:46-9.

17. Kukreja S, Ambekar S, Sin AH, Nanda A. Occipitocervical fusion surgery: review of operative techniques and results. J Neurol Surg B Skull Base. 2015; 76:331-9.

18. Huang DG, Hao DJ, He BR, Wu QN, Liu TJ, Wang XD, Guo H, Fang XY. Posterior atlantoaxial fixation: a review of all techniques. Spine J. 2015;15: 2271-81.

19. Sim HB, Lee JW, Park JT, Mindea SA, Lim J, Park J. Biomechanical evaluations of various C1-c2 posterior fixation techniques. Spine (Phila Pa 1976). 2011;36: E401-7.

20. Sutterlin CE, Bianchi JR, Kunz DN, Zdeblick TA, Johnson WM, Rapoff AJ. Biomechanical evaluation of occipitocervical fixation devices. J Spinal Disord. 2001;14:185-92.

21. Ryken TC, Aarabi B, Dhall SS, Gelb DE, Hurlbert RJ, Rozzelle CJ, Theodore N, Walters BC, Hadley MN. Management of isolated fractures of the atlas in adults. Neurosurgery. 2013;72(Suppl 2):127-31.

22. Hein C, Richter HP, Rath SA. Atlantoaxial screw fixation for the treatment of isolated and combined unstable Jefferson fractures-experiences with 8 patients. Acta Neurochir (Wien). 2002;144:1187-92.

23. Dickman C. Re: Ruf M, Melcher R, Harms J. Transoral reduction and osteosynthesis $\mathrm{C} 1$ as a function-preserving option in the treatment of unstable Jefferson fractures. Spine (Phila Pa 1976). 2004; 29:823-827. Spine (Phila Pa 1976). 2004;29(19):2196-7.

24. Koller H, Resch H, Tauber M, Zenner J, Augat P, Penzkofer R, Acosta F, Kolb K, Kathrein A, Hitzl W. A biomechanical rationale for C1-ring osteosynthesis as treatment for displaced Jefferson burst fractures with incompetency of the transverse atlantal ligament. Eur Spine J. 2010;19:1288-98.

25. Li-Jun L, Ying-Chao H, Ming-Jie Y, Jie P, Jun T, Dong-Sheng Z. Biomechanical analysis of the longitudinal ligament of upper cervical spine in maintaining atlantoaxial stability. Spinal Cord. 2014;52:342-7. 
26. He B, Yan L, Zhao Q, Chang Z, Hao D. Self-designed posterior atlas polyaxial lateral mass screw-plate fixation for unstable atlas fracture. Spine J. 2014;14: 2892-6.

27. Li L, Teng H, Pan J, Qian L, Zeng C, Sun G, Yang M, Tan J. Direct posterior C1 lateral mass screws compression reduction and osteosynthesis in the treatment of unstable jefferson fractures. Spine (Phila Pa 1976). 2011;36: E1046-51.

28. Yin QS, Li XS, Bai ZH, Mai XH, Xia H, Wu ZH, Ma XY, Ai FZ, Wang JH, Zhang K. An 11-year review of the TARP procedure in the treatment of atlantoaxial dislocation. Spine (Phila Pa 1976). 2016;41:E1151-8.

\section{Publisher's Note}

Springer Nature remains neutral with regard to jurisdictional claims in published maps and institutional affiliations.

- fast, convenient online submission

- thorough peer review by experienced researchers in your field

- rapid publication on acceptance

- support for research data, including large and complex data types

- gold Open Access which fosters wider collaboration and increased citations

- maximum visibility for your research: over $100 \mathrm{M}$ website views per year

At $\mathrm{BMC}$, research is always in progress. 